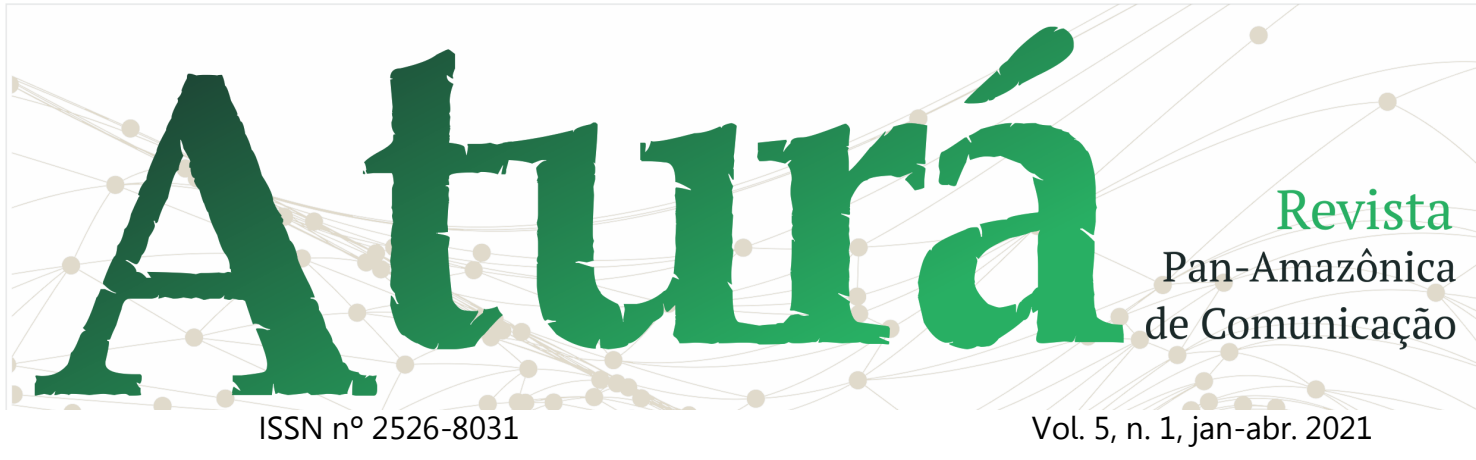

\title{
COMUNICAÇÃO PÚBLICA NO TWITTER: UMA ANÁLISE DOS PERFIS DOS TRIBUNAIS REGIONAIS ELEITORAIS DO NORTE
}

Public communication on Twitter: an analysis of the profiles of the Northern Regional Electoral Courts

Comunicación pública en Twitter: un análisis de los perfiles de las Cortes Electorales Regionales del Norte

Maurílio Luiz Hoffmann da Silva, Universidade Federal do Tocantins ${ }^{1}$

\section{RESUMO}

O artigo inicia com uma discussão teórica sobre os conceitos de "comunicação pública" e "mídias e redes sociais digitais", ambos em processo de construção. Acredita-se que o surgimento e popularização dessas ferramentas podem fomentar práticas comunicativas; aumentar a interação entre órgãos públicos e cidadãos, entre Estado e sociedade. A parte empírica consiste em uma análise quali-quantitativa dos perfis dos Tribunais Regionais Eleitorais do norte do Brasil no Twitter. São realizadas visitas aos perfis dos tribunais, a fim de coletar dados como data de criação, seguidores, seguindo e quantidade de tweets. Também é realizada a coleta de tweets das contas, que são classificados entre tweet, reply e retweet. As análises demonstram que os perfis não são, em geral, utilizados como ferramenta de conversação ou interação, mas apenas divulgação de informação. Considerase que os recursos disponibilizados e o potencial da ferramenta não é plenamente explorado pelos órgãos.

PALAVRAS-CHAVE: História da mídia digital; Comunicação pública; Mídias e redes sociais digitais; Twitter.

\section{ABSTRACT}

The paper starts with a theoretical discussion on the concepts of "public communication" and "digital media and social networks", both in the process of being constructed. It is believed that the emergence and popularization of these tools can foster communicative

\footnotetext{
${ }^{1}$ Técnico em informática (IFTO. 2007). Bacharel em Comunicação Social (UFT. 2010). Mestre em Estudos da União Europeia (Uni Salzburg, Austria. 2017). Mestrando em Comunicação e Cultura (UFT).
} 


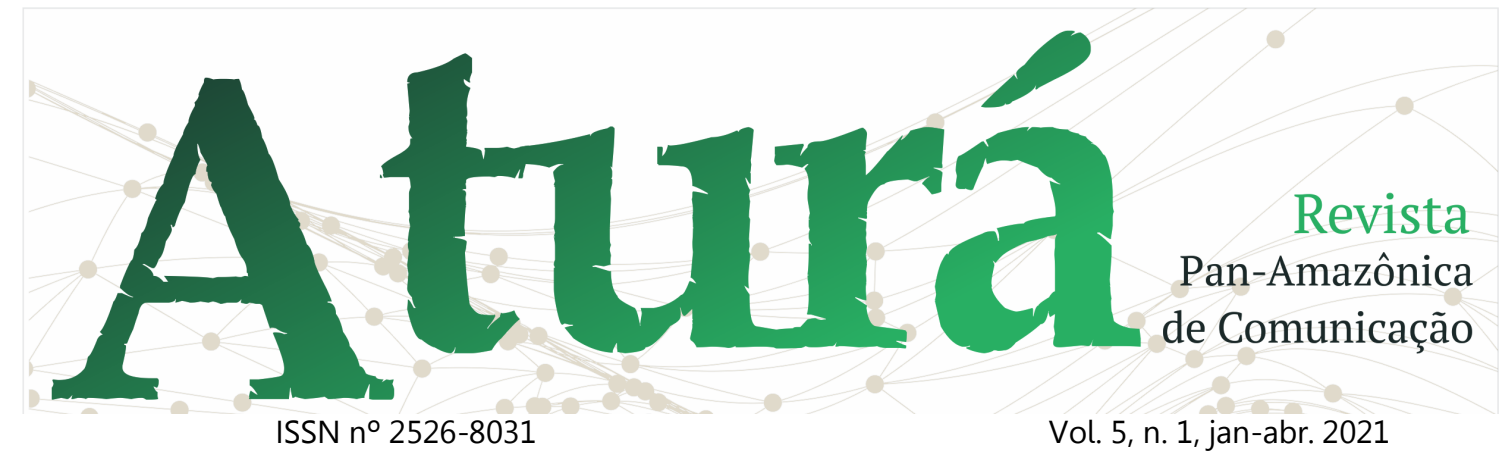

practices; increase the interaction between public agencies and citizens, between the State and society. The empirical part consists of a qualitative and quantitative analysis of the profiles of the Regional Electoral Courts of northern Brazil on Twitter. Visits are made to the court profiles, in order to collect data such as creation data, followers, following and number of tweets. Tweets are also collected, and classified in three categories: tweet, reply and retweet. The analyzes demonstrate that the profiles are, in general, not used as a tool of conversation or interaction, but only information dissemination. It is considered that the resources made available and the potential of the tool are not fully exploited by the agencies.

KEYWORDS: History of digital media; Public communication; Digital social media and networks; Twitter.

\section{RESUMEN}

El trabajo comienza con una discusión teórica sobre los conceptos de "comunicación pública" y "medios digitales y redes sociales", ambos en proceso de construcción. Se cree que el surgimiento y popularización de estas herramientas puede fomentar prácticas comunicativas; Incrementar la interacción entre los organismos públicos y la ciudadanía, entre el Estado y la sociedad. La parte empírica consiste en un análisis cualitativo y cuantitativo de los perfiles de las Cortes Electorales Regionales del norte de Brasil en Twitter. Se realizan visitas a los perfiles del tribunal, con el fin de recoger datos como datos de creación, seguidores, seguimiento y número de tweets. Los tweets también se recopilan y clasifican en tres categorías: tweet, respuesta y retweet. Los análisis demuestran que los perfiles, en general, no se utilizan como herramienta de conversación o interacción, sino únicamente de difusión de información. Se considera que los recursos puestos a disposición y el potencial de la herramienta no son aprovechados plenamente por las agencias.

PALABRAS CLAVE: Historia de los medios digitales; Comunicación publica; Redes y medios sociales digitales; Twitter 


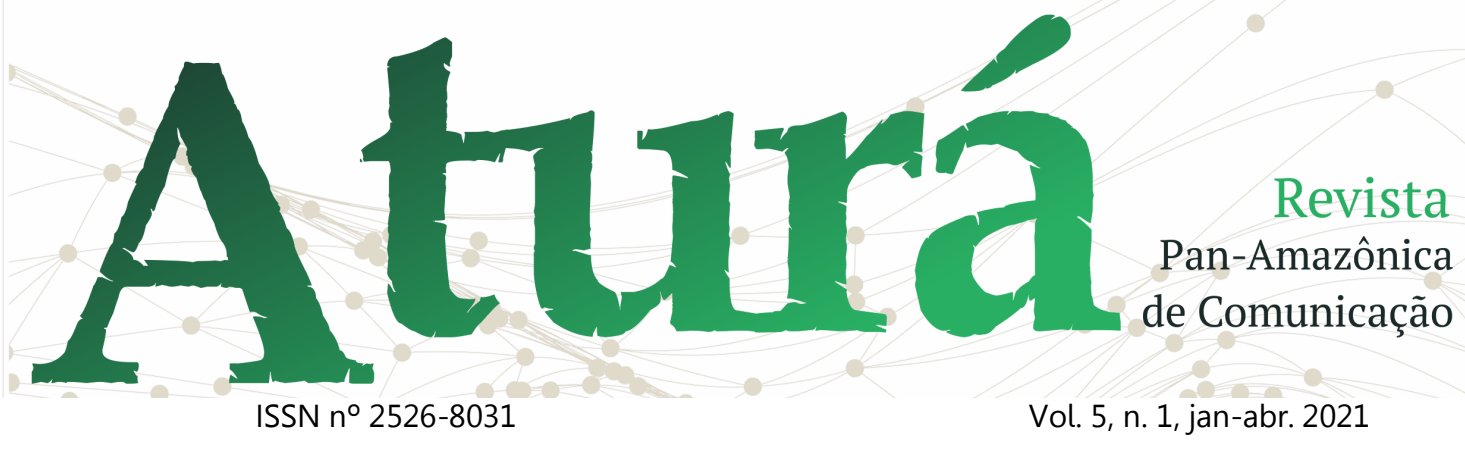

\section{Introdução}

Por força da globalização e do desenvolvimento tecnológico das últimas décadas a sociedade está cada vez mais conectada. $\mathrm{O}$ advento e popularização da Internet mudou hábitos, abreviou o tempo, diminuiu distâncias e conectou pessoas.

Comunicar, portanto, ficou mais fácil, principalmente após a popularização das comumente conhecidas como "redes sociais". Pessoas, empresas e órgãos públicos estão cada vez mais presentes "nas redes". No entanto, é necessária atenção em como essas redes estão sendo adotadas pela sociedade e pelo governo. E como as práticas comunicacionais estão se desenvolvendo neste novo espaço de interação.

Neste sentido, o artigo inicia com uma proposta de apresentação de conceitos fundamentais à análise: "comunicação pública" e "mídias e redes sociais digitais". O primeiro é um conceito que já vem sendo trabalhado há alguns anos na academia, contudo ainda está em construção e com algumas divergências entre os autores.
Resumidamente, pode-se dizer que comunicação pública se dá quando processos de comunicação existem entre as partes que formam a opinião pública sobre temas de interesse comum. A comunicação exercida pelos órgãos públicos é por essência uma prática de comunicação pública, que, apesar de apresentar um grande potencial, é muitas vezes reduzida à mera divulgação de informações.

Já o conceito de mídias e redes sociais digitais, apesar de ter começado a tomar maior relevância recentemente, com a popularização dos sites de redes sociais, também não é um conceito amplamente aceito nem entre teóricos, nem no senso comum. Além de ainda alguma confusão teórico-conceitual.

Partindo destes conceitos, surge 0 objetivo deste trabalho: analisar como os Tribunais Regionais Eleitorais da região norte estão executando sua comunicação pública nas redes e mídias sociais digitais.

Depois da construção teóricoconceitual, a seção 3 apresenta o corpus analisado: os perfis no Twitter dos 7 


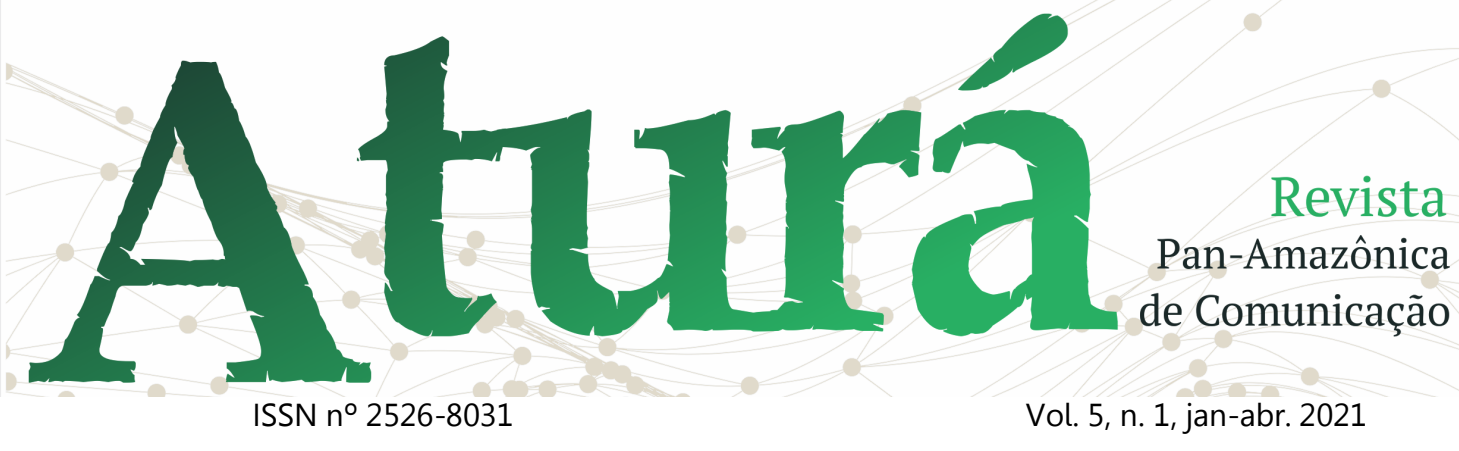

Tribunais Regionais Eleitorais que compõem a região norte do Brasil.

É realizada, então, uma análise quali-quantitativa em duas etapas: primeiro apresentando os perfis e números de seguindo, seguidores e tweets, segundo, analisando e classificando os tweets publicados pelos perfis em três categorias (Tweet, Reply, e Retweet).

As análises revelam que é comum entre os perfis seguirem poucas contas, 0 que é um sinal de pouca disposição para interação e comunicação. Demonstra-se ainda que o uso mais comum do Twitter é para simples divulgação de informação; o número de respostas e retweets é baixo. Em resumo, a comunicação pública realizada não atende aos princípios teóricos apresentados.

\section{Comunicação pública nas mídias redes sociais digitais}

Neste item serão discutidos os conceitos de "comunicação pública" e de "mídias e redes sociais digitais" a partir dos mais relevantes autores da área. Os

objetivos do item são: correlacionar os dois conceitos, mostrando como a migração das relações interpessoais para - ambiente digital podem fomentar práticas de comunicação pública; e munir o leitor dos conceitos teóricos a serem investigados nas análises empíricas desenvolvidas no item 3.

O conceito de "comunicação pública" é um conceito ainda em construção e que vem tomando alguma atenção na pesquisa em comunicação (MONTEIRO, 2012). De acordo com Brandão (2012, p. 1), "a expressão comunicação pública (CP) vem sendo usada com múltiplos significados, frequentemente conflitantes, dependendo do país, do autor e do contexto em que é utilizada." A autora destaca que diante de tamanha diversidade o conceito não é claro nem mesmo como uma área de atuação profissional delimitada.

Neste sentido, Duarte (2012), afirma que este é um objeto de estudo recente e de particular interesse dos comunicadores que atuam nos Três Poderes. 


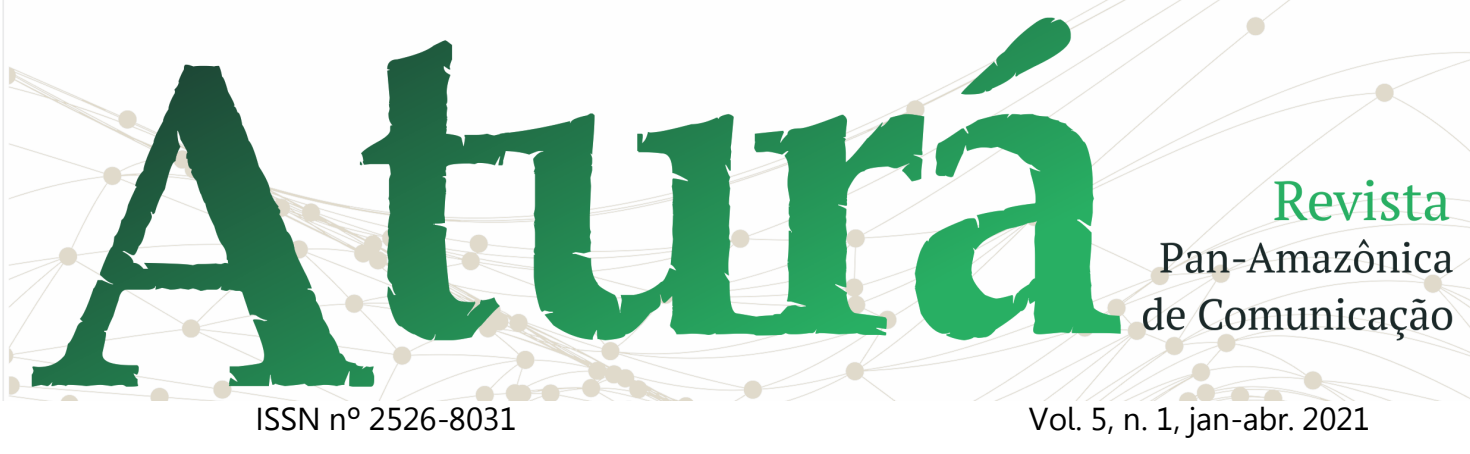

Comunicação pública, no Brasil, é uma expressão que não especifica um conjunto de conhecimento, áreas, profissões ou estruturas, estando mais próximo de se caracterizar como um etos, uma postura de perceber e utilizar a comunicação como instrumento de interesse coletivo para fortalecimento da cidadania. No setor público, em que tem maior potencial de desenvolvimento, incorpora o pressuposto da transparência em um tema historicamente relacionado à busca de visibilidade e legitimidade e que às vezes assume viés claramente político de culto à personalidade ou promoção institucional (DUARTE, 2012, p. 60).

Brandão (2012), explica que o conceito de comunicação pública tem se relacionado com cinco áreas diferentes de conhecimento e atividade profissional, são elas:

1. CP identificada com os conhecimentos e técnicas da área de Comunicação Organizacional;

2. CP identificada com comunicação científica;

3. CP identificada com comunicação do Estado e/ou governamental;

4. CP identificada como comunicação política;

5. CP identificada com estratégias de comunicação da sociedade civil organizada.
Do ponto de vista profissional, Duarte $(2012$, p. 57) afirma que a atuação em comunicação pública exige:

1. compromisso em privilegiar o interesse público em relação ao interesse individual ou corporativo;

2. centralizar o processo no cidadão;

3. tratar comunicação como um processo mais amplo do que informação;

4. adaptação dos instrumentos às necessidades, possibilidades e interesses dos públicos;

5. assumir a complexidade da comunicação, tratando-a como um todo uno.

Entende-se, portanto, a partir de Brandão (2012) e Duarte (2012) que as práticas de comunicação pública são em geral estudadas e executadas por comunicadores atuantes nos órgãos da administração pública e que voltam suas atenções para assuntos de interesse público com foco na sociedade, abraçando a complexidade da comunicação e superando práticas meramente informativas.

Na área acadêmica, Brandão (2012) e Koçouski (2012) destacam a importância 


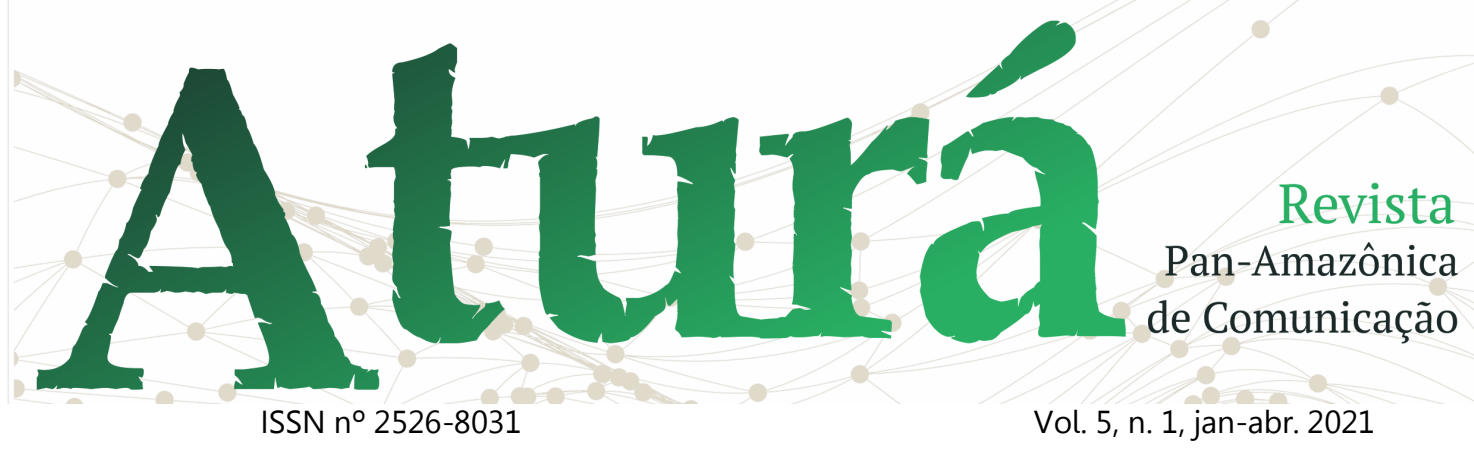

do autor francês Pierre Zémor, para as pesquisas brasileiras. Zémor publicou em 1995 o livro La communication publique (A Comunicação Pública), que serve de base teórica para muitos autores e pesquisadores brasileiros. A começar por Brandão (2012, p. 31) que define comunicação pública como "processo de comunicação que se instaura na esfera pública entre o Estado, o Governo e a Sociedade e que se propõe a ser um espaço privilegiado de negociação entre os interesses das diversas instâncias de um poder constitutivas da vida pública no país".

Já para Novelli (apud BRANDÃO, 2012, p. 18), "a comunicação pública é aquela praticada pelos órgãos responsáveis pela administração pública que tem importância significativa para o exercício da participação política e da cidadania".

Koçouski (2012, p. 75), reforça que para Zémor as finalidades da comunicação pública não podem ser dissociadas daquelas inerentes às instituições públicas, que têm como função: "a) informar; b) escutar; c) contribuir para assegurar a relação social e; d) acompanhar as mudanças de comportamento e das organizações sociais."

A autora define comunicação pública como

uma estratégia ou ação comunicativa
que acontece quando o olhar é
direcionado ao interesse público, a
partir da responsabilidade que o
agente tem (ou assume) de recolher e
atender o direito dos cidadãos à
informação e participação em assuntos
relevantes à condição humana ou vida
em sociedade. Ela tem como objetivos
promover a cidadania e mobilizar o
debate de questões afetas à
coletividade, buscando alcançar, em
estágios mais avançados, negociações
e consensos (KOÇOUSKI, 2012, p.
75).

Nota-se, assim, que fazer comunicação pública vai além de simplesmente informar a sociedade, envolvendo também práticas de estímulo ao diálogo e conversação na esfera pública entre instâncias que compõem a sociedade sobre assuntos que sejam de interesse comum. Neste sentido, Matos (2012, p. 47) ressalta que esse entendimento da comunicação pública como espaço da/para sociedade organizada é relativamente recente. 


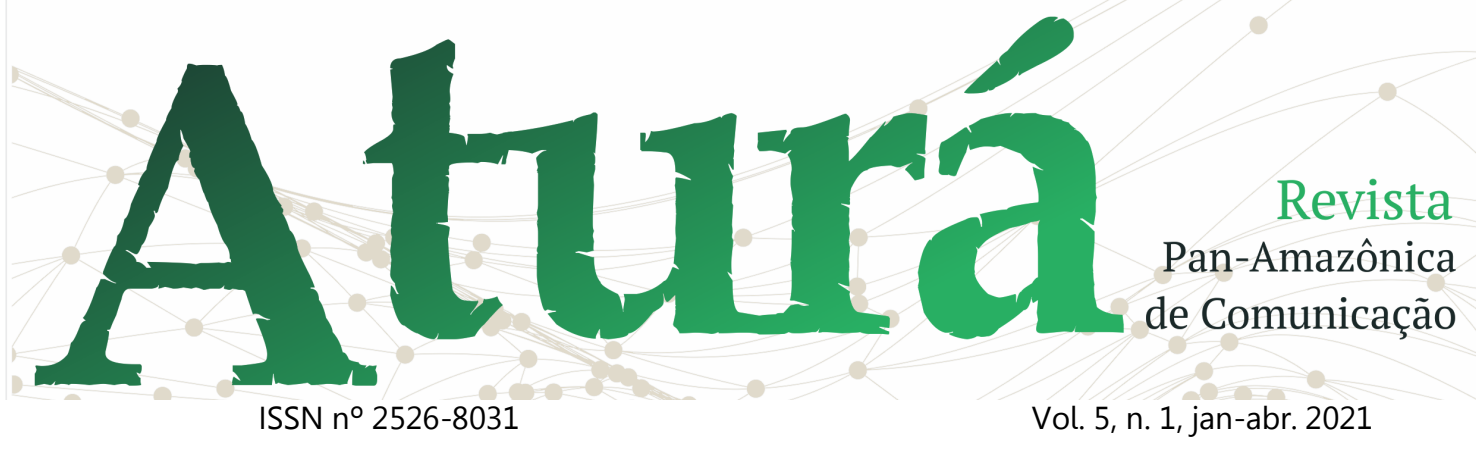

Trazendo os conceitos abordados até agora para a realidade contemporânea da sociedade organizada em redes digitais (CASTELLS, 2007), cabe ressaltar a importância das mídias e redes sociais digitais como possíveis espaços para a interação e o diálogo entre órgãos públicos e cidadãos, entre governo e sociedade.

Nascimento (2012, p. 294) aponta que os órgãos públicos "têm adotado os múltiplos canais que possibilitam grande interatividades e o compartilhamento de informações com os cidadãos", o que pode ser observado com a quantidade de perfis criados nos sites de redes sociais.

O conceito "redes sociais" é anterior ao surgimento da internet e não deve ser confundido com sites de redes sociais. Como afirmam Recuero, Bastos e Zago (2015, p. 23):

as redes sociais são metáforas para a estrutura de agrupamentos sociais. Elas são constituídas pelas relações entre indivíduos e vão servir como estrutura fundamental para a sociedade. São, assim, uma forma de olhar grupos sociais, onde se percebem as relações e os laços sociais como conexões e os indivíduos como atores que estão unidos por essas conexões, formando o tecido social.

As redes sociais criadas em ambientes digitais têm relação direta com o conceito de sociedade em rede desenvolvido por Castells (2007). Elas podem ser consideradas ferramentas adotadas na contemporaneidade para suprir lacunas existentes no mundo analógico, aproximando as pessoas temporal e geograficamente. São espaços de socialização, divulgação de informação, educação, conversação, entre outros usos. Tornaram-se, dessa forma, elementos constituintes da cibercultura (LÉVY, 1999; LEMOS, 2004).

De acordo com Recuero (2009), uma rede social é definida como um conjunto de dois elementos: atores e suas conexões. Conceito que pode ser aplicado para redes tanto offline quanto online. Atualizando o conceito para ambientes digitais, Boyd e Ellison (2007) definem as redes sociais como serviços baseados na web, os quais permitem aos indivíduos (1) construir um perfil público ou semipúblico em um sistema pré-definido; (2) definir uma lista de outros usuários com os quais eles compartilham alguma conexão; 


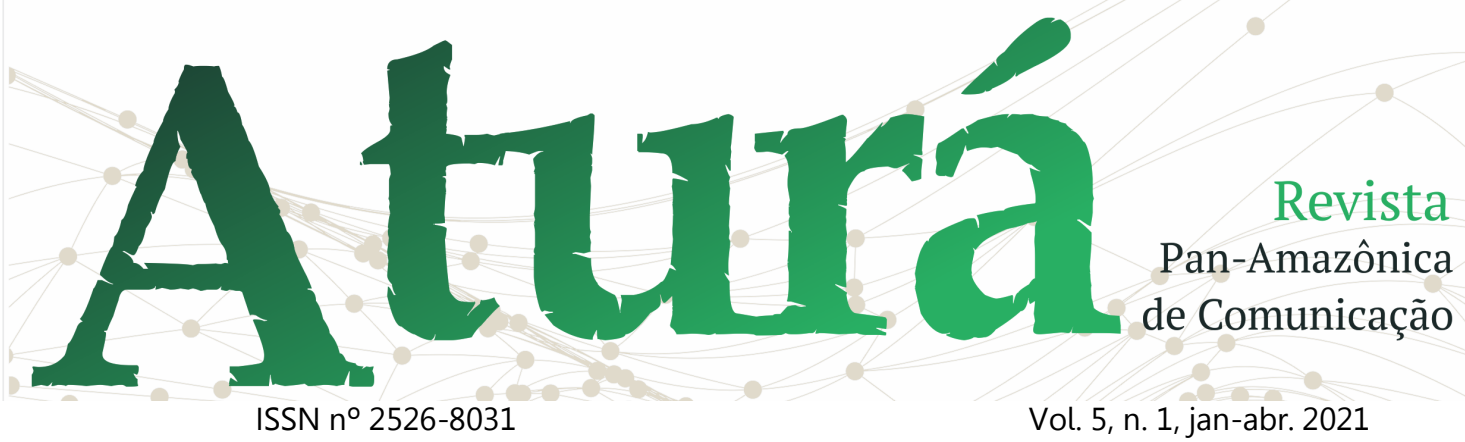

e (3) ver e navegar não apenas suas conexões, como também aquelas feitas por outras pessoas dentro do sistema.

Redes sociais, portanto, estão relacionadas aos sujeitos e às conexões existentes entre eles. Já o conceito "mídias sociais" está mais voltado para o suporte em si. O termo mídias sociais é comumente utilizado em contradição aos meios de comunicação de massa (TV, rádio, jornal impresso, por exemplo). Recuero, Bastos e Zago (2015, p. 31) afirmam que mídia social "se refere a um fenômeno emergente, que tem início com a apropriação dos sites de rede social pelos usuários".

Ambos os termos - redes sociais e mídias sociais - , no entanto, são utilizados na literatura acadêmica e adotados no senso comum como sinônimos substituíveis.

Com o intuito de pacificar estas discussões conceituais adota-se neste artigo a proposta de Colnago (2015). A autora afirma que, enquanto alguns pesquisadores tentam problematizar a definição dos conceitos, ela prefere uma abordagem mais integradora, que facilite a compreensão dos leitores. Como, por exemplo, o agrupamento genérico proposto por Peruzzo (2013, p. 79):

as mídias e redes sociais virtuais (YouTube, Flickr, Facebook, Instagram, Twitter etc.) se constituem em canais de informação, em ambientes comunicacionais, em pontos de encontro, enfim, em redes e, às vezes, até em comunidades, que facilitaram os relacionamentos (entre os que estão conectados), a articulação entre as pessoas e as ações conjugadas [...]. Claro que servem ainda de arena de debate, de difusão, acesso e troca de informação.

A adoção da expressão "mídias e redes sociais digitais" compreende, portanto, a "definição, a formação e a interação de grupos com interesses comuns que se relacionam e se sustentam por meio de processos contínuos de comunicação no ambiente digital, viabilizados a partir do uso da internet e de dispositivos tecnológicos" (COLNAGO, 2015, p. 10).

Devido à sua organização em rede através do ciberespaço, as mídias e redes sociais digitais rompem a lógica clássica da comunicação de massa - um emissor e vários receptores - abrindo a possibilidade de comunicação direta entre governo e 


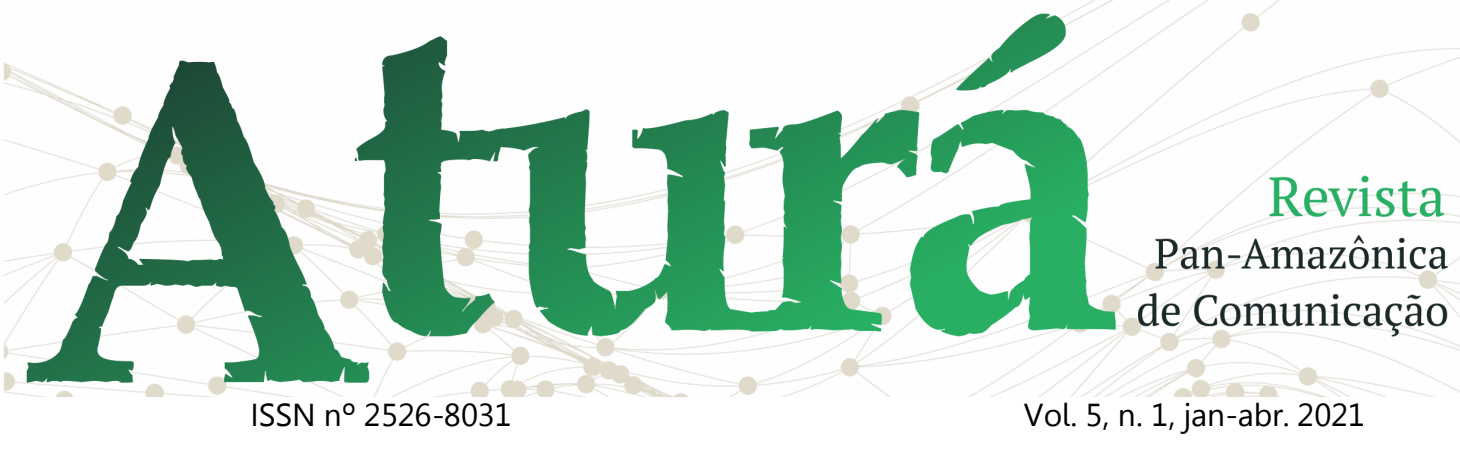

sociedade e vice-versa, tornando-se, portanto, ambiente propício para existência de práticas de comunicação pública. Um novo espaço para que os processos de comunicação realizados na esfera pública aconteçam.

Ressalta-se, assim, que não só os cidadãos estão se fazendo presentes nas redes sociais. Como aponta Nascimento (2012, p. 293), "as instituições públicas vêm buscando novos canais de participação e interatividade no ambiente digital, fato que pode ser observado pela quantidade de perfis oficiais dos órgãos do governo federal nas redes sociais".

Segundo a pesquisa TIC Governo Eletrônico 2019, realizada pelo Centro Regional de Estudos para 0 Desenvolvimento da Sociedade da Informação (CETIC.BR, 2019), 85\% dos órgãos públicos federais e estaduais com acesso à internet possuem conta ou perfil em rede social online (99\% dos órgãos do judiciário). Destes, 83\% possui uma área ou pessoa responsável pelo relacionamento com cidadãos nas redes sociais (87\% dos órgãos do judiciário). Ainda segundo a pesquisa, $60 \%$ destes órgãos postam ou atualizam o conteúdo em seus perfis diariamente $(58 \%$ no judiciário) e outros 28\% (31\% no judiciário) atualizam pelo menos uma vez por semana. Ou seja, aproximadamente $88 \%$ dos perfis de órgãos públicos estaduais e federais são atualizados pelo menos uma vez por semana ou mais.

O fato de haver uma área ou pessoa responsável pelo relacionamento com os cidadãos através das mídias e redes sociais digitais demonstra, ainda, a preocupação e o investimento dos órgãos públicos neste ramo de comunicação. Espera-se, portanto, que o uso das mídias e redes sociais digitais por parte dos órgãos públicos vá além da mera divulgação de informações, como acontece normalmente nos portais governamentais, e faça uso de práticas de interação direta com a sociedade proporcionadas pelos sites de redes sociais. Pois, como afirma Bueno (2015, p. 129), "um nível superior, mais bem elaborado, de atuação das organizações nas mídias sociais transcende o da veiculação de conteúdo para se focar na criação de um espaço de relacionamento específico e competente". 


\section{A \\ ISSN n² 2526-8031}

É exatamente esse relacionamento nas mídias e redes sociais digitais entre os tribunais eleitorais da região norte e a sociedade que será analisado no próximo item.

\section{O judiciário brasileiro no Twitter}

Seguindo a tendência apontada por Nascimento (2012) e comprovada na pesquisa CETIC.BR (2019) os órgãos do judiciário brasileiro estão presentes em muitas das mídias e redes sociais digitais. O ramo especializado da justiça eleitoral foi intencionalmente escolhido por carregar não apenas como função típica a aplicação da lei, como também a realização das eleições, que é o evento que garante, na organização do estado democrático de direito brasileiro, a manifestação da vontade do povo. O recorte na região norte se deu intencionalmente por causa do evento para o qual o artigo foi submetido.
Revista Pan-Amazônica de Comunicação

Vol. 5, n. 1, jan-abr. 2021

Dentre os sites de redes sociais existentes, o Twitter é o que apresenta maior abertura para coleta de dados, além de ser um ambiente que estimula práticas comunicacionais, como será apresentado mais à frente. Por isso, este foi o site de rede social escolhido para análise.

A pergunta de pesquisa que a análise visa a responder é como os tribunais eleitorais da região norte do Brasil estão realizando comunicação pública nas redes sociais?

Para responder à esta pergunta, propõe-se neste artigo uma análise qualiquantitativa dividida em duas etapas: (1) apresentação dos perfis e análise números de seguindo, seguidores e tweets, e (2) análise e classificação dos tweets publicados pelos perfis em três categorias (Tweet; Reply; e Retweet);

A Tabela 1 apresenta os dados coletados na visita, realizada no dia 20 de setembro de 2020.

Tabela 1: Resumo dos perfis no Twitter

\begin{tabular}{|c|c|c|c|c|c|}
\hline Perfil & Criado em & Tweets & Seguidores & Seguindo & Verificado \\
\hline
\end{tabular}




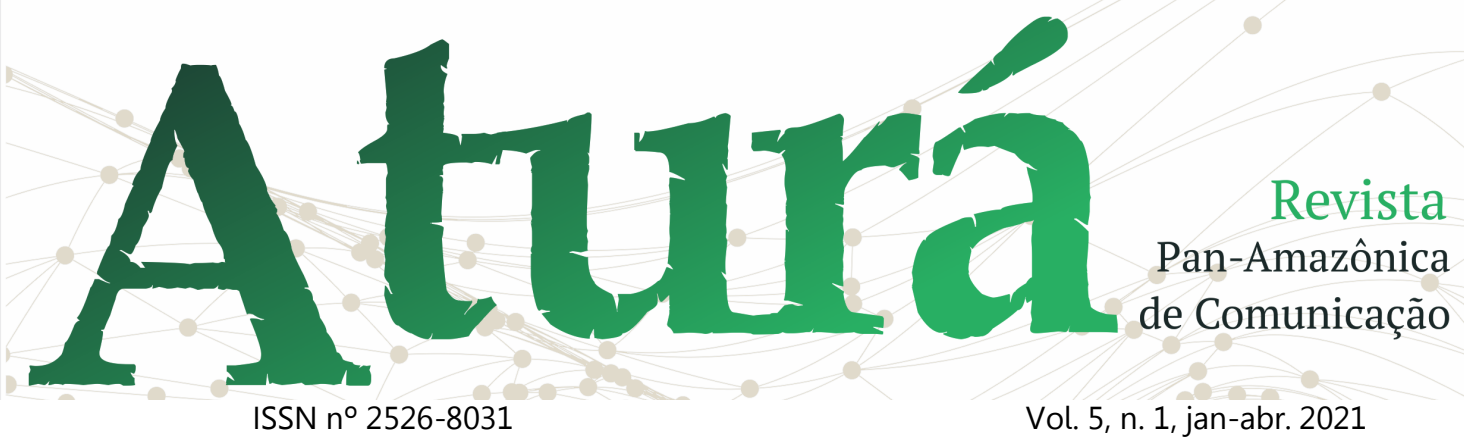

\begin{tabular}{|l|l|c|c|c|c|}
\hline & & (aprox.) & & & \\
\hline @treacre & Março 2011 & 76 & 361 & 38 & Não \\
\hline $\begin{array}{l}\text { @treamazon } \\
\text { as }\end{array}$ & Junho 2012 & 1240 & 1800 & 27 & Sim \\
\hline @treamapa & Maio 2011 & 5212 & 6660 & 71 & Sim \\
\hline @tredopara & $\begin{array}{l}\text { Novembro } \\
2012\end{array}$ & 0 & 47 & 3 & Não \\
\hline @tre_ro & $\begin{array}{l}\text { Fevereiro } \\
2012\end{array}$ & 2021 & 1526 & 338 & Não \\
\hline @tre_rr & Junho 2010 & 2900 & 4459 & 72 & Não \\
\hline $\begin{array}{l}\text { @tretocantin } \\
\text { s }\end{array}$ & Março 2010 & 5471 & 3928 & 84 & Sim \\
\hline
\end{tabular}

Fonte: elaboração do autor, 2020.

O primeiro dado que a Tabela 1 apresenta é a data de criação dos perfis. É possível notar que todos os perfis foram criados entre 2010 e 2012, sendo o mais novo deles o perfil do TRE-PA, criado em novembro de 2012, ou seja, com aproximadamente 8 anos.

A segunda coluna mostra uma grande divergência entre os perfis. Acre e Pará com números muito baixos -76 e 0 , respectivamente -; Amazonas, Rondônia e Roraima com uma média entre 1000 e
2000 tweets, e Amapá e Tocantins com mais de 5200 posts.

O número de seguidores também diverge bastante entre as contas, e, contrariando o que seria senso comum considerando suas populações, os Estados com mais seguidores são: Amapá, Roraima e Tocantins.

O número de seguindo é um dado interessante para se analisar, pois ele pode demonstrar quão aberto o perfil está aberto à interação. Em outras palavras, 


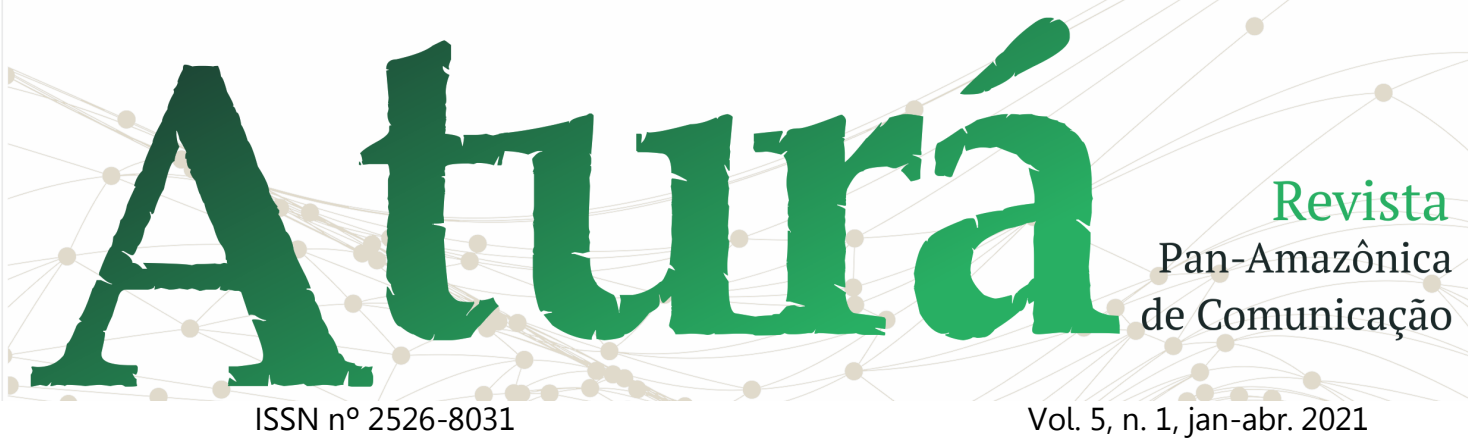

quem segue poucas contas tem a tendência de interagir pouco. Pode-se perceber na coluna "Seguindo" da Tabela 1 que, com exceção do TRE-RO que seguem 338 contas, todos os outros seguem menos de 85 .

A última consideração a se fazer é com relação às contas verificadas, que são as contas que recebem o selo de autenticidade do Twitter. Essa informação é relevante principalmente por conta do contexto de propagação de desinformação contemporâneo. Recorrer a perfis oficiais é uma das atitudes recomendadas e a ausência do selo de autenticidade do Twitter pode ferir a credibilidade do perfil. Dentre os tribunais analisados, Acre, Pará, Rondônia e Roraima não possuem o referido selo.

Após a visita aos perfis, utilizou-se a ferramenta $T A G S^{2}$ para coleta de tweets das contas analisadas. A ferramenta realiza a busca no Twitter através da $\mathrm{API}^{3}$ e salva os tweets encontrados em uma planilha no Google planilhas. A ferramenta foi

2 Disponível em: <https://tags.hawksey.info/>. Acesso em: 25 ago. 2020.

3 Application Programming Interface, em português, Interface de Programação de Aplicativos. 


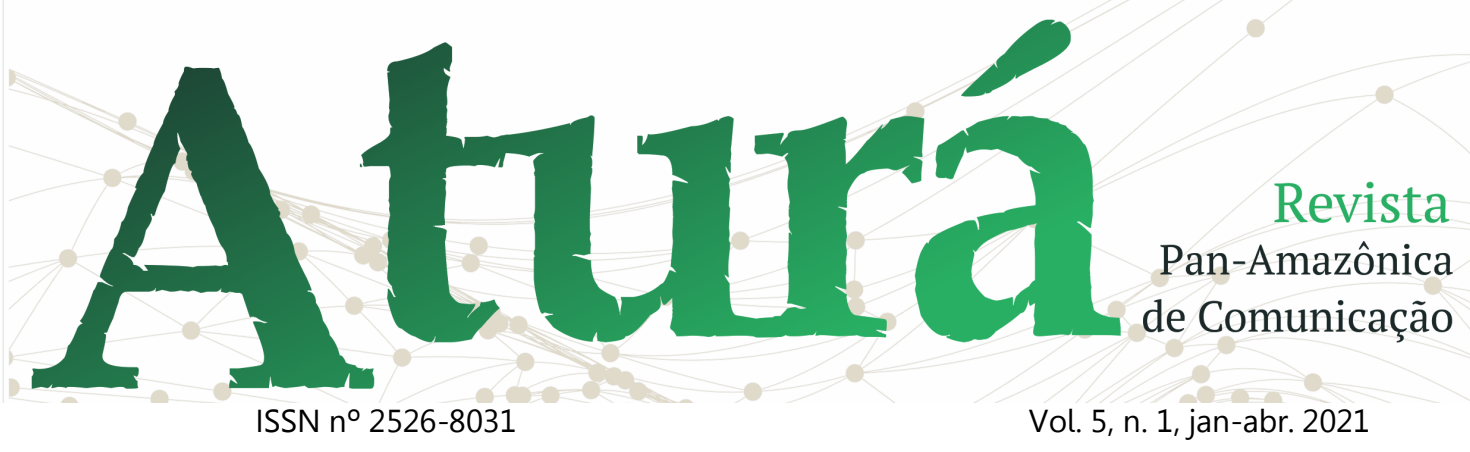

informação para uma grande quantidade de receptores - neste caso, seguidores.

Reply. resposta a algum seguidor ou outro perfil que tenha mencionado a conta do órgão. No contexto desta pesquisa, é onde o órgão manifesta que está de fato disposto a ouvir e conversar com os cidadãos, colocando em prática, portanto, o conceito de comunicação pública voltada à sociedade e ao interesse público construído no item anterior.

Retweet. no Twitter, um "RT" é uma republicação de um tweet já postado pelo órgão ou por outra conta, num sentido de republicar o conteúdo para os seguidores do perfil. É importante contabilizar os retweets, pois eles demonstram que órgão, além de estar disposto a conversar - o que se manifesta mais apropriadamente nas replies - também está atento ao que as contas que o perfil segue postam e faz uma espécie de curadoria de conteúdos relevantes postados por outros, mais uma vez reforçando práticas de comunicação pública.

A Tabela 2 traz um resumo dos tweets coletados. A primeira informação que se destaca, na coluna Tweet, é que a maioria dos tweets coletados pertencem a esta categoria. Esse número demonstra que, apesar de todo o potencial de estimular processos de comunicação entre sociedade e órgãos públicos propiciado pelas mídias e redes sociais digitais, e ainda, apesar de mais de vários anos usando o Twitter como ferramenta de comunicação, os tribunais eleitorais da região norte ainda não exploram os possíveis usos da ferramenta e interagem pouco com seus cidadãos e eleitores.

Tabela 2: Resumo dos tweets coletados

\begin{tabular}{|c|c|c|c|c|}
\hline Perfil & Tweet & Reply & Retweet & Total \\
\hline $\begin{array}{c}\text { @treamazon } \\
\text { as }\end{array}$ & $\begin{array}{c}587 \\
(98,3 \%)\end{array}$ & $\begin{array}{c}0 \\
(-)\end{array}$ & $\begin{array}{c}10 \\
(0,7 \%)\end{array}$ & $\begin{array}{c}597 \\
(100 \%)\end{array}$ \\
\hline @treamapa & 522 & 0 & 75 & 597 \\
\hline
\end{tabular}




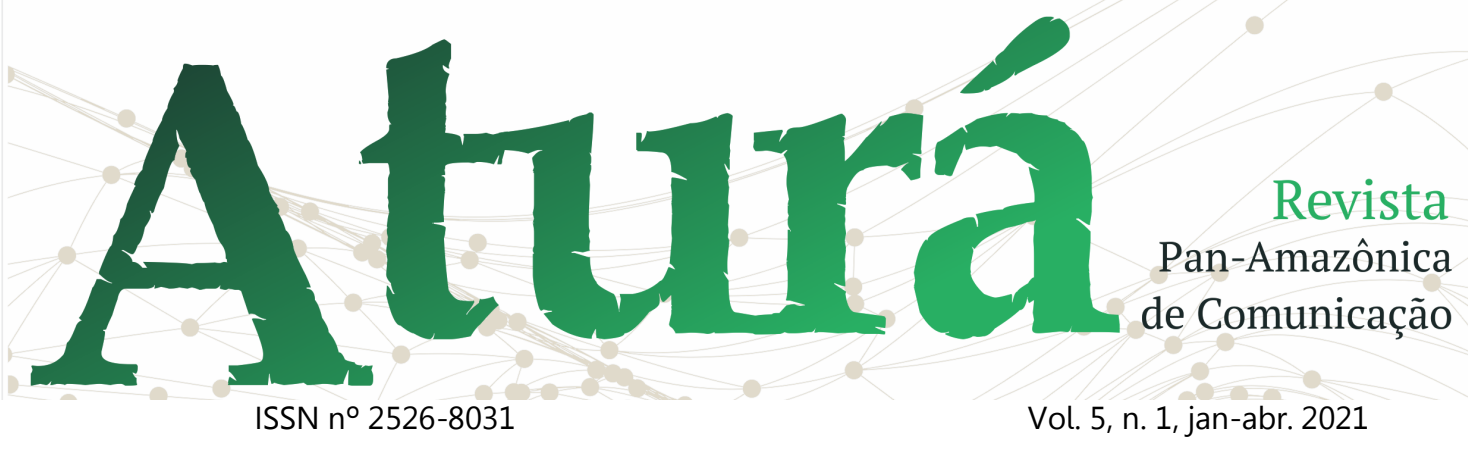

\begin{tabular}{|c|c|c|c|c|}
\hline & $(87,4 \%)$ & $(-)$ & $(12,6 \%)$ & $(100 \%)$ \\
\hline @tre_ro & $\begin{array}{c}427 \\
(71,5 \%)\end{array}$ & $\begin{array}{c}0 \\
(-)\end{array}$ & $\begin{array}{c}170 \\
(28,5 \%)\end{array}$ & $\begin{array}{c}597 \\
(100 \%)\end{array}$ \\
\hline @tre_rr & $\begin{array}{c}496 \\
(83 \%)\end{array}$ & $\begin{array}{c}0 \\
(-)\end{array}$ & $\begin{array}{c}101 \\
(16 \%)\end{array}$ & $\begin{array}{c}597 \\
(100 \%)\end{array}$ \\
\hline $\begin{array}{c}\text { @tretocanti } \\
\text { ns }\end{array}$ & $\begin{array}{c}456 \\
(76,4 \%)\end{array}$ & $\begin{array}{c}54 \\
(9 \%)\end{array}$ & $\begin{array}{c}87 \\
(14,6 \%)\end{array}$ & $\begin{array}{c}597 \\
(100 \%)\end{array}$ \\
\hline
\end{tabular}

Fonte: elaboração do autor, 2020

O número de replies é zero para todos os tribunais, com exceção do Tocantins, cujas respostas a outros perfis contabilizou $9 \%$ do total de posts publicados. Como apontado anteriormente, era de se esperar pouca interação, uma vez que os perfis analisados seguem poucas contas. Não responder nenhuma conta demonstra que a maioria dos órgãos têm utilizado $\mathrm{O}$ Twitter apenas como meio de propagação de informações e não como ferramenta de comunicação e interação com a sociedade.

O número de retweets também é relativamente baixo. O perfil do TRE-RO destaca-se dos demais com 170 republicações. Como apontado anteriormente, RTs podem significar uma espécie de curadoria de conteúdos para os seguidores, o que aparentemente todos os tribunais têm feito, uns mais que outros.

Tendo em vista as análises realizadas é possível concluir que, pelo menos no Twitter e considerando as limitações das coletas, os órgãos tribunais eleitorais da região norte do brasil não exercem comunicação pública conforme o conceito construído no item 2. Não é comum aos órgãos analisados responderem aos cidadãos, o que pode ser notado não apenas no fato de seguirem poucas contas, como também de terem contabilizado poucos replies.

\section{Considerações finais}

Como visto no item 2, comunicação pública tem como pressuposto o ato de 


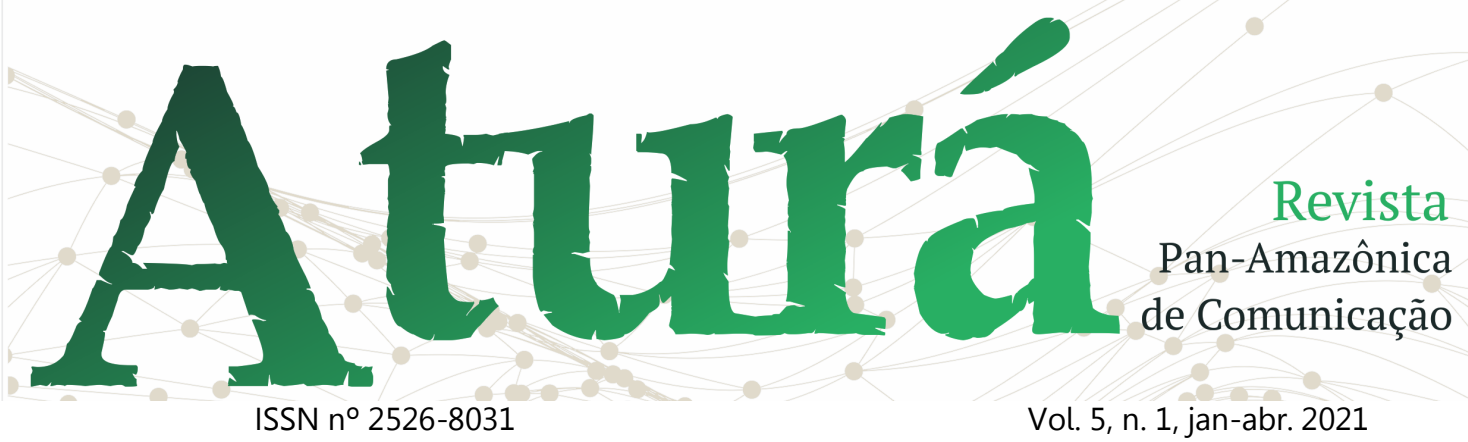

comunicar; ir além da mera divulgação de informação. Além disso, o foco na sociedade e nos temas de interesse comum também fazem parte deste conceito que ainda está em construção.

Neste contexto, surgem as redes e mídias sociais digitais, que podem ser usadas e adotadas como ferramentas ou plataformas onde a comunicação pública poderia acontecer. Um novo espaço para a opinião pública interagir e se desenvolver. Plataformas que estão sendo cada vez mais adotadas por pessoas, empresas e ainda pelos órgãos públicos.

Entretanto, as análises realizadas no item 3 revelaram que é uma prática comum entre os perfis seguirem poucas contas, apesar de terem muitos seguidores. Isso pode ser um sinal de pouca disposição para interagir no Twitter. Além disso, ficou demonstrado que o uso mais comum do Twitter é para simples divulgação de informação; houve pouca interação em repostas e RTs.

Tendo em vista as limitações desta pesquisa - como unicidade de plataforma; número limitado de tweets, limitações da
API do Twitter; entre outras - e os resultados das análises realizadas, outras possibilidades de pesquisa podem surgir: analisar outras plataformas; realizar entrevistas com os gestores de comunicação para melhor compreender a realidade das unidades e rotinas de trabalho; até mesmo analisar o porquê de tribunais de Estados pequenos terem mais seguidores do que Estados com uma maior população, são alguns exemplos.

Parece necessário, no entanto, e em querendo desenvolver a comunicação pública nesta justiça especializada que sejam revistas as estratégias de comunicação dos órgãos, bem como haja investimentos em equipes e capacitações para uma melhor utilização dos sites de redes sociais.

\section{Referências}

BOYD, D.M.; ELLISON, N.B. Social Network Sites: Definition, History, and Scholarship. Journal of Computer-Mediated Communication. v. 13, n. 1, 2007. p. $210-$ $230 . \quad$ Disponivel em: https://doi.org/10.1111/j.10836101.2007.00393.x. Acesso em: 4 dez. 2019. 


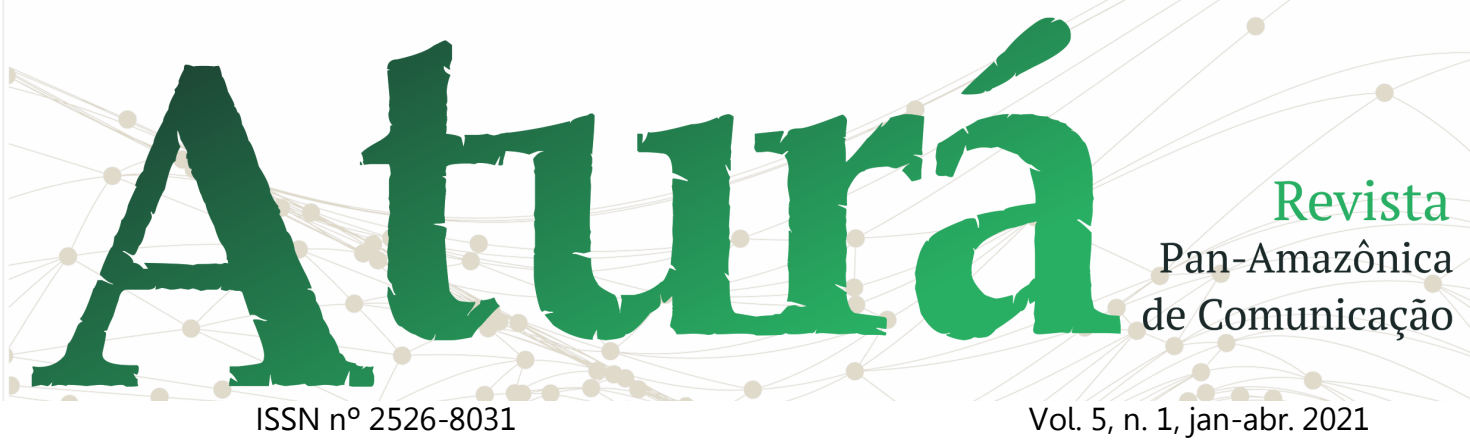

BRANDÃO, E. P. Conceito de comunicação pública. In: Duarte, Jorge (org). Comunicação Pública: Estado, mercado, sociedade e interesse público. 3. ed. São Paulo: Atlas, 2012. p. 1-33.

BUENO, W. C. Estratégias de comunicação para as mídias sociais. In: BUENO, W. C. Estratégias de comunicação nas mídias sociais. Barueri, SP: Manole, 2015. p. 123144.

CASTELLS, M. A sociedade em rede. 10 ed. São Paulo: Paz e Terra, 2007.

CETIC.BR. Pesquisa Governo eletrônico 2019. Disponível em <https://cetic.br/pt/pesquisa/governoeletronico/indicadores/>. Acesso em: 28 ago. 2020.

COLNAGO, C. K. Mídias e redes sociais digitais: conceitos e práticas. In: BUENO, W. C. Estratégias de comunicação nas mídias sociais. Barueri, SP: Manole, 2015. p. 1-22.

DUARTE, J. Instrumentos de comunicação pública. In: Duarte, Jorge (org). Comunicação Pública: Estado, mercado, sociedade e interesse público. 3. ed. São Paulo: Atlas, 2012. p. 59-71.

KOÇOUSKI, M. Comunicação pública: construindo um conceito. In: Matos, Heloiza (Org). Comunicação pública: interlocuções, interlocutores e perspectivas. São Paulo: ECA/USP, 2012. p. 71-96.

LEMOS, A. Cibercultura: tecnologia e vida social na cultura contemporânea. 2. ed. Porto Alegre: Sulina, 2004.

LÉVY, P. Cibercultura. São Paulo: Ed. 34, 1999.
MATOS, H. Comunicação pública, esfera pública e capital social. In: Duarte, Jorge (org). Comunicação Pública: Estado, mercado, sociedade e interesse público. 3 . ed. São Paulo: Atlas, 2012. p. 47-58.

MONTEIRO, G. F. A singularidade da comunicação pública. In: Duarte, Jorge (org). Comunicação Pública: Estado, mercado, sociedade e interesse público. 3. ed. São Paulo: Atlas, 2012. p. 34-46.

NASCIMENTO, L. L. do. Comunicação pública nas redes sociais digitais. In: MATOS, H. (Org.) Comunicação pública: interlocuções, interlocutores e perspectivas. São Paulo: ECA/USP, 2012. p. 289-310.

PERUZZO, C. M. K. Movimentos sociais, redes virtuais e mídia alternativa no junho em que "o gigante acordou"(?). Matrizes Revista do Programa de Pós-Graduação em Ciências da Comunicação da Universidade de São Paulo. Ano 7, n. 2, jul./dez. 2013. p. 73-93. Disponível em: <https://www.revistas.usp.br/matrizes/arti cle/download/69407/71976/ >. Acesso em: 4 dez. 2019.

RECUERO, R.; BASTOS, M.; ZAGO, G. Análise de redes para mídia social. Porto Alegre: Sulina, 2015.

RECUERO, R. Redes Sociais na Internet. Porto Alegre: Sulina, 2009. 


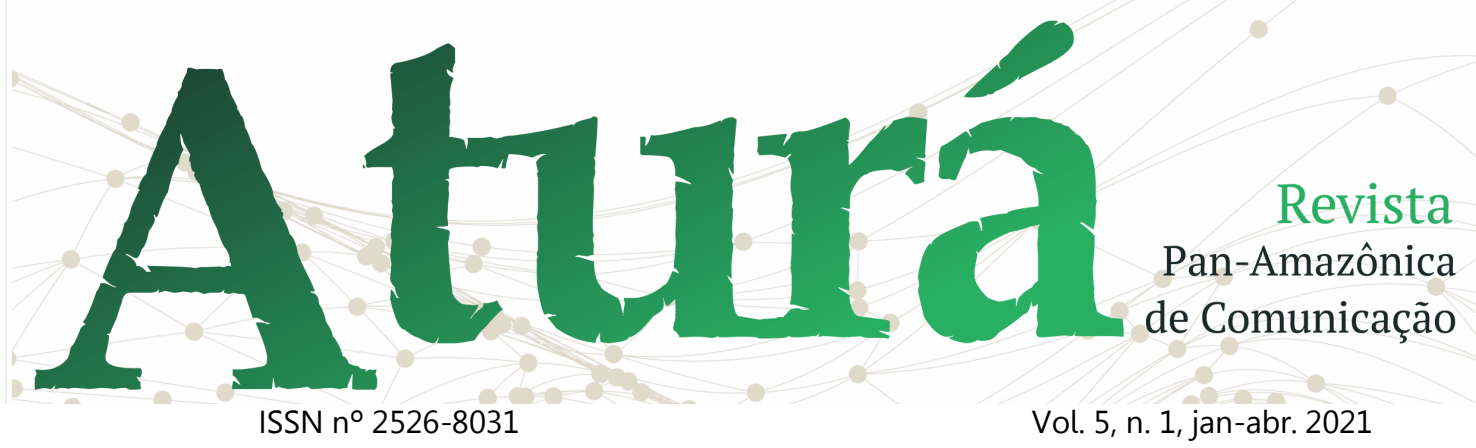

